\title{
Enjoyment of Life
}

National Cancer Institute

\section{Source}

National Cancer Institute. Enjoyment of Life. NCI Thesaurus. Code C104080.

The level of happiness or contentment that an individual professes, or is observed to display with regards to their life situation. 